\title{
Effects of Nonionic Surfactants on Xanthan Gum Production: a Survey on Cellular Interactions
}

\author{
Tahereh Ghashghaei ${ }^{1}$, Mohammad Reza Soudi ${ }^{*}$, Saman Hoseinkhani ${ }^{2}$, Morteza Shiri ${ }^{3}$ \\ ${ }^{1}$ Department of Microbiology, Faculty of Biological Science, Alzahra University, Tehran, Iran \\ ${ }^{2}$ Department of Biochemistry, Faculty of Biological Science, Tarbiat Modares University, Tehran, Iran \\ ${ }^{3}$ Department of Chemistry, Faculty of Physics and Chemistry, Alzahra University, Tehran, Iran \\ "Corresponding author: Mohammad Reza Soudi, Department of Microbiology, Faculty of Biological Science, Alzahra University, Vanak, Tehran, Iran \\ P.O. Box: 1993893973. Tel: +98 -21 85692733, Fax:+98 21 88058912, E-mail: msoudi@alzahra.ac.ir
}

Received: 16 Feb. 2016 Revised: 11 Jan. 2018 Accepted: 11 Mar. 2018 Published online: 18 Apr. 2018

\begin{abstract}
Background: Xanthomonas campestris is a biopolymer producing gram negative bacterium. Production of xanthan biopolymer can be affected by different extrinsic factors as well as surfactants. Hitherto, effects of nonionic surfactants on xanthan production have been studied in a limited number of articles.

Objective: In the present study, nonionic surfactants were used to pursue their effects on improvement of xanthan production. Moreover, a number of cellular consequences upon the treatment were investigated with impacts on gum production.

Materials and Methods: Effects of different nonionic surfactants (Tween 20, Tween 80 and Triton X100) on xanthan production and Xanthomonas campestris cells were assessed by ultramicroscopy (SEM), changes in culture turbidity, leakage of sugars and ATP, and quality of xanthan (i.e. pyruvate content and determination of polymer molecular weight).

Results: The nonionic surfactant Tween 20 increased ATP (3.2 folds) and sugar leakage (3.1 folds). Furthermore, they caused cell shape alteration. Tween 80 improved both xanthan production $\left(11 \mathrm{~g} . \mathrm{L}^{-1}\right)$ and viscosity of the product (1368 cP), while the total biomass remained unchanged $\left(2.2 \mathrm{~g} . \mathrm{L}^{-1}\right)$. Molecular weight of xanthan was enhanced (from 23 to 59 million $\mathrm{Da})$. Toxic effect of 5\% (v/v) Triton X 100 decreased the turbidity of culture to 120 NTU and total biomass was diminished to 1 g. $\mathrm{L}^{-1}$. Tween 20 caused the loss of ATP and sugar leakage and led to lower xanthan production. It had no effect on biomass content.

Conclusions: In general, amounts of surfactants that bacterial cells can tolerate seem to be helpful in substrate and metabolite transportation, and enzyme activities involved in xanthan biosynthesis and release. Surfactants induce harsh damages to cell barriers, preventing the growth and adversely affecting quantity and quality of xanthan gum.

Keywords: Surfactant, Xanthomonas campestris, Xanthan gum
\end{abstract}

\section{Background}

Xanthomonas is an aerobic gram negative phytopathogen, affecting varieties of plants (1). Xanthan gum, a heteropolysaccaride, is produced by Xanthomonas campestris, next to a number of members from Xanthomonadaceae family. This polymer is made up of repeated pentasaccharide units of glucose, mannose and glucuronic acid in 2:2:1 ratio. Xanthan has been used extensively in food industry as the emulsifier and stabilizer next to its other applications in oil, cosmetic, textile and paper industries (1).

Improvement of xanthan production and optimization of relevant factors, such as surfactants, that enhance its quantity have been the topic of interest (2). Detergents can elevate oxygen transfer and therefore improve xanthan production and its rheological features such as viscosity $(3,4)$. Application of detergents also helps in higher production of hydrolyzing enzymes (5-8), but the mechanism(s) of which has mostly remained elusive. Increased cell membrane permeability, modified lipid metabolism, and elevated enzyme release are amongst the feasible modes of action that lead to higher xanthan secretion (5-8). Surfactants affect bacterial membranes and more specifically disturb the less-selective outer membrane $(3,4,9)$ through which and in our case cause better release of the xanthan gum.

Copyright (C) 2017 The Author(s); Published by National Institute of Genetic Engineering and Biotechnology. This is an open access article, distributed under the terms of the Creative Commons Attribution-NonCommercial 4.0 International License (http://creativecommons.org/licenses/ by-nc/4.0/) which permits others to copy and redistribute material just in noncommercial usages, provided the original work is properly cited. 


\section{Objective}

The aim of present study was to investigate the cellular connections with greater xanthan production in the presence of nonionic surfactants.

\section{Materials and Methods}

\subsection{Microorganism, Cultivation and Maintenance}

Xanthomonas campestris pathovar. campestris strain b82 was obtained from Laboratory of Industrial Microbiology at Alzahra University (Tehran, Iran). Pure cultures of the bacterium were sub-cultured on Yeast Malt Agar (YMA) slants and maintained at $4{ }^{\circ} \mathrm{C}$.

\subsection{Exopolysaccharide Production}

The pre-cultures in 100-mL flasks containing $20 \mathrm{~mL}$ of Yeast Malt Broth (YMB) were incubated at $28^{\circ} \mathrm{C}$ on an orbital shaker at $150 \mathrm{rpm}$ for $16 \mathrm{~h}$ and used as inocula. The inocula were added to $500-\mathrm{mL}$ flasks containing the production medium and incubated under the same conditions for $72 \mathrm{~h}$ (10). The production medium was formulated using sucrose (20 g.L $\left.\mathrm{L}^{-1}\right)$, ammonium sulfate $\left(1\right.$ g. $\left.\mathrm{L}^{-1}\right)$ plus a cocktail of organics and mineral salts with overall concentration of 5.4 g.L.-1 $(10)$.

Cultures were supplemented with surfactants, namely Tween 20 (polyoxyethylene sorbitan monolaurate), Tween 80 (polyoxyethylene sorbitan monooleate), and Triton X100 (polyoxyethylene octylphenyl ether) after $24 \mathrm{~h}$. Different concentrations $(0.05 \%, 0.1 \%, 0.5 \%, 1 \%$, $2 \%, 3 \%, 4 \%, 5 \%$ and $6 \% \mathrm{v} / \mathrm{v}$ ) of the surfactants were used.

\subsection{Determination of Production Parameters}

The apparent viscosity of fermentation broth was measured at $22{ }^{\circ} \mathrm{C}$ by Brookfield viscometer system using spindle number 3 at $60 \mathrm{rpm}$. Raw xanthan was precipitated with 1.5 volumes of isopropyl alcohol and heat dried. Xanthan concentration (g.L $\left.\mathrm{L}^{-1}\right)$ in flask cultures was measured as a function of time in the presence of surfactants with $5 \%(\mathrm{v} / \mathrm{v})$ concentration.

Dry cell weights of cultures were measured at the end of fermentation as the total biomass. The cells were collected after centrifugation of diluted culture at $12,000 \times g$ for $30 \mathrm{~min}$ at $4{ }^{\circ} \mathrm{C}$. The pelleted biomass was consequently washed with diluted ethyl alcohol to remove traces of xanthan before being subjected to another centrifugation for $10 \mathrm{~min}$ at $9000 \mathrm{rpm}$. The cells were dried in a hot air oven for $3 \mathrm{~h}$ at $105^{\circ} \mathrm{C}$ and weighed (11).

Estimated total biomass was subtracted from the raw xanthan and assumed as the weight of pure xanthan. Production yield and productivity were calculated.
Results from the experiments were analyzed statistically using one sample $t$ tests to determine differences; a $p$ value of $<0.05$ was considered significant.

\subsection{Turbidity Test}

At the end of fermentation, culture flasks were sampled and in each case the turbidity was measured using a turbidometer on the basis of Nephelometric Turbidity Units (NTU) (9). Results from the turbidity assays were analyzed statistically as mentioned above.

\subsection{Scanning Electron Microscopy (SEM)}

Thirty hour cultures, $6 \mathrm{~h}$ after addition of surfactants, were sampled for SEM ultramicroscopy. Fixation and dehydration of samples were carried out according to Kang et al. (12). The samples were gently kept dried using silica gel and mounted on metallic stubs, gold coated $(\sim 100 \AA)$ with a sputter coater and viewed under Scanning Electron Microscope using $20 \mathrm{kV}$ accelerating potential.

\subsection{ATP Leakage Assay}

To determine ATP leakage, bacterial cells were harvested from $30 \mathrm{~h}$ cultures and supernatants were used for ATP assay after centrifugation at $9000 \times g$. ATP assay was carried out using bioluminescence method based on the evaluation of the emission light by an ATP-dependent luciferase activity (maximum emission $\sim 560 \mathrm{~nm}$ at $\mathrm{pH}$ $=7.8$ ) (13). In a luminometer tube, $10 \mu \mathrm{L}$ of luciferase reagent and $10 \mu \mathrm{L}$ of luciferin $(5 \mathrm{mM})$ were mixed with $20 \mu \mathrm{L}$ of the samples/standards. Luminescence was monitored over a period of $10 \mathrm{~s}$ in relative light units (RLUs) at $560 \mathrm{~nm}$.

\subsection{Determination of Sugar Leakage \\ 3.7.1. Sugar Profiling}

Samples of supernatants $(1 \mu \mathrm{L})$ from $30 \mathrm{~h}$ production cultures were obtained and analyzed by Thin Layer Chromatography (TLC) with a solvent system of 1-butanol- acetic acid- water $(2: 1: 1 \mathrm{v} / \mathrm{v} / \mathrm{v})$. The products were visualized by heating a TLC plate at $110{ }^{\circ} \mathrm{C}$ for 5 min after spraying it with $10 \%(\mathrm{v} / \mathrm{v})$ sulfuric acid in ethanol (14).

\subsubsection{Reductive Sugar Assay}

Samples from supernatants of 30 - $\mathrm{h}$ production cultures were examined to measure reductive sugars leaked from the cells using DNS method (15).

\subsection{Characterization of the Product}

3.8.1. Determination of Pyruvate Content

The percentage of pyruvate covalently attached to the 
polysaccharide was determined by a lactate dehydrogenase enzymatic assay method after hydrolysis of pure xanthan samples in $2 \mathrm{~N} \mathrm{HCl}$ at $100{ }^{\circ} \mathrm{C}$ for $3 \mathrm{~h}(16)$.

\subsubsection{Determination of Xanthan Molecular Weight}

The average molecular weight of purified xanthan was determined by Gel Permeation Chromatography (GPC) on water Ultrahydragel 2000 column at $1 \mathrm{~mL} \cdot \mathrm{min}^{-1}$ flow rate using water as mobile phase and RI detector $(17,18)$.

\subsection{Statistical Analysis}

Statistical analysis was carried out by IBM SPSS Statistics version 20 using one sample $t$ test to determine the mean differences (9).

\section{Results}

\subsection{Exopolysaccharide Production}

Exopolysaccharide production and related viscosity were measured at the end of fermentation process in cultures exposed to surfactants (Tables 1,2 ). In contrast to Tween 20 and Triton X100, in the presence of Tween 80 an increase in xanthan production (11 g. $\mathrm{L}^{-1}$ ) was occurred and apparent viscosity of the culture was amplified $(1368 \mathrm{cP})$. All of the positive and negative effects were significant $(p<0.05)$ (Tables 1, 2). Xanthan production (g. $\left.\mathrm{L}^{-1}\right)$ was also measured as a function of time in presence of surfactants. The xanthan concentration in different cultures was compared in a time course from $\mathrm{t}=36 \mathrm{~h}$ to $\mathrm{t}=72 \mathrm{~h}$ and the results showed that the difference between control and surfactant containing cultures were statistically significance (Fig. 1).

\subsection{Determination of Dry Cell Weight}

The amounts of biomass in fermented cultures containing 5\% Tween 80 and 5\% Tween 20 were the same as control $\left(2.2 \mathrm{~g} . \mathrm{L}^{-1}\right)$, but in culture with $5 \%$ Triton $\mathrm{X} 100$ a decline in quantity of biomass was recorded $\left(1.0\right.$ g.L $\left.\mathrm{L}^{-1}\right)$

\subsection{Turbidity Assay}

Turbidity of cultures containing Tween 20 and Tween 80 remained close to the control (Table 3). However, after addition of Triton X100, the turbidity of the culture was drastically decreased from 1785 NTU (control) to 75 NTU. All of the recorded differences in turbidity were statistically significant other than the case of Tween 20 .

\subsection{Cell Size and Cell Shape Changes}

Culture samples were collected $6 \mathrm{~h}$ following the addition of the surfactants. The samples were prepared for SEM. Changes in the bacterial cell size were evident especially in the presence of Triton X100. Bacterial cell size decreased in the presence of all surfactants comparing to that of the control. The cell shape transformation from rod to round was recorded in case of Triton X100. Signs of bacterial division were observed in the presence of all surfactants as well as the control (Fig. 2).

Table 1. Exopolysaccharide production $\left(\mathrm{g} \cdot \mathrm{L}^{-1}\right)$ with different nonionic surfactants and concentration (\%).

\begin{tabular}{|c|c|c|c|c|c|c|c|c|c|}
\hline \multirow{2}{*}{$\begin{array}{l}\text { Surfactant } \\
\text { concentration } \\
(\%)\end{array}$} & \multicolumn{3}{|c|}{ Triton X100 } & \multicolumn{3}{|c|}{ Tween 80} & \multicolumn{3}{|c|}{ Tween 20} \\
\hline & 竭 & 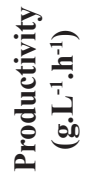 & 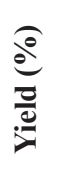 & 兽 & 音 & $\frac{\substack{\partial \\
\frac{\partial}{2}}}{\partial}$ & : & 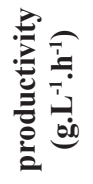 & $\frac{\overbrace{}^{e}}{2}$ \\
\hline 0.05 & $9.6 \pm 0.05$ & 0.13 & 48 & $10.1 \pm 0.05$ & 0.14 & 50 & $9.8 \pm 0.01$ & 0.14 & 49 \\
\hline 0.1 & $9.5 \pm 0.11$ & 0.13 & 47 & $10.2 \pm 0.05$ & 0.14 & 51 & $9.5 \pm 0.04$ & 0.13 & 47 \\
\hline 0.5 & $9.5 \pm 0.10$ & 0.13 & 47 & $10.9 \pm 0.15$ & 0.15 & 54 & $9.7 \pm 0.01$ & 0.13 & 48 \\
\hline 1 & $9.5 \pm 0.05$ & 0.13 & 47 & $10.8 \pm 0.05$ & 0.15 & 54 & $9.8 \pm 0.01$ & 0.14 & 49 \\
\hline 2 & $9.8 \pm 0.05$ & 0.14 & 49 & $10.6 \pm 0.05$ & 0.15 & 53 & $9.6 \pm 0.14$ & 0.13 & 48 \\
\hline 3 & $9.7 \pm 0.11$ & 0.13 & 48 & $10.4 \pm 0.01$ & 0.14 & 52 & $9.3 \pm 0.01$ & 0.12 & 46 \\
\hline 4 & $9.8 \pm 0.05$ & 0.14 & 49 & $10.8 \pm 0.07$ & 0.15 & 54 & $9.8 \pm 0.08$ & 0.14 & 49 \\
\hline 5 & $9.6 \pm 0.10$ & 0.13 & 48 & $11 \pm 0.1$ & 0.15 & 55 & $9.8 \pm 0.01$ & 0.14 & 49 \\
\hline 6 & $9.5 \pm 0.06$ & 0.13 & 47 & $10.3 \pm 0.06$ & 0.14 & 51 & $9.3 \pm 0.01$ & 0.12 & 46 \\
\hline
\end{tabular}

Xanthan production of control (culture without surfactant) was $10.00 \pm 0.04$ g.L.

$p$ value in all experiments was $<0.05$ 
Table 2. Exopolysaccharide viscosity (cP) with different nonionic surfactant.

\begin{tabular}{lccc}
\hline $\begin{array}{l}\text { Surfactant concentration } \\
(\%)\end{array}$ & \multicolumn{3}{c}{ Viscosity (cP) in the presence of } \\
& Triton X100 & Tween 80 & Tween 20 \\
\hline 0.05 & $951 \pm 7.63$ & $1041 \pm 3.51$ & $874 \pm 3.21$ \\
0.1 & $972 \pm 6.24$ & $1137 \pm 7.57$ & $895 \pm 1.15$ \\
0.5 & $918 \pm 2.51$ & $1000 \pm 6.00$ & $537 \pm 1.00$ \\
1 & $947 \pm 3.60$ & $1293 \pm 1.00$ & $731 \pm 1.00$ \\
2 & $912 \pm 7.63$ & $1268 \pm 2.51$ & $820 \pm 2.00$ \\
3 & $927 \pm 6.02$ & $1202 \pm 11.53$ & $812 \pm 1.52$ \\
4 & $918 \pm 6.11$ & $1281 \pm 2.64$ & $932 \pm 2.08$ \\
5 & $915 \pm 1.52$ & $1368 \pm 6.24$ & $909 \pm 1.52$ \\
6 & $912 \pm 1.00$ & $1280 \pm 3.00$ & $902 \pm 1.52$ \\
\hline
\end{tabular}

Xanthan viscosity of control (culture without surfactant) was $1250 \pm 5.00 \mathrm{cP}$ $p$ value in all experiments was $<0.05$

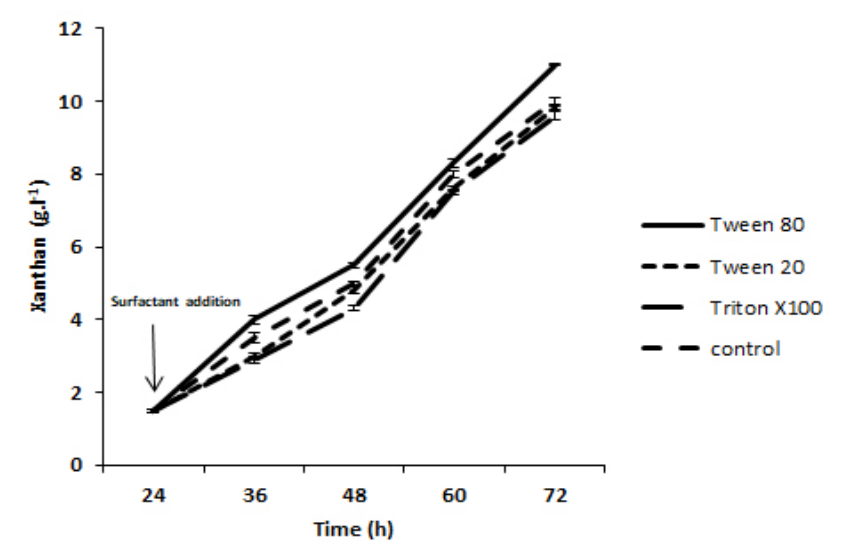

Figure 1. Xanthan production $\left(\mathrm{g} . \mathrm{L}^{-1}\right)$ in the presence of different surfactants with $5 \%(\mathrm{v} / \mathrm{v})$ concentration and control culture without any surfactant. Surfactants were added in $\mathrm{t}=$ 24 of cultivation. From $\mathrm{t}=36 \mathrm{~h}$ to $\mathrm{t}=72 \mathrm{~h}$ difference between xanthan production in the presence of surfactant compared with control was statistically significant.

\subsection{Assessment of Damage to the Cell Barriers}

Both of the ATP leakage and release of reduced sugars were assumed as the signs of damage to the cell membrane and outer membrane.

In contrast to the control, the results showed a significant ATP leakage from the cells exposed to the surfactants. Tween 20 induced the greatest amount of ATP leakage $(0.4 \mu \mathrm{M})$ compared to those of the other surfactants (Fig. 3).

The results showed that greater amounts of reduced sugars were found in the supernatant of the culture in the presence of surfactants compared to that of the control. Tween 20 induced release of the maximum amount of reduced sugars $\left(0.22 \mathrm{mg} . \mathrm{L}^{-1}\right)$, but Triton $\mathrm{X} 100$ resulted to the release of the minimum amount of reduced sugars (Fig. 3). Release of simple sugars including glucose and fructose was confirmed according to the results obtained from TLC. TLC

Table 3. Turbidity (NTU) of cultures after $72 \mathrm{~h}$.

\begin{tabular}{lccc}
\hline Surfactant concentration (\%) & \multicolumn{3}{c}{ Turbidity (NTU) in the presence of } \\
& Triton X100 & Tween 80 & Tween 20 \\
\hline 0.05 & $750( \pm 8.48)$ & $1771( \pm 9.89)^{*}$ & $1748( \pm 21.21)$ \\
0.1 & $630( \pm 12.72)$ & $1615( \pm 12.02)$ & $1675( \pm 14.84)$ \\
0.5 & $476( \pm 7.77)$ & $1615( \pm 14.14)$ & $1766( \pm 8.48)$ \\
1 & $318( \pm 7.77)$ & $1537( \pm 10.60)$ & $1747( \pm 10.60)$ \\
2 & $296( \pm 9.19)$ & $1512( \pm 14.84)$ & $1725( \pm 21.92)$ \\
3 & $273( \pm 1.41)$ & $1489( \pm 8.48)$ & $1703( \pm 14.14)$ \\
4 & $215( \pm 3.53)$ & $1465( \pm 7.52)$ & $1698( \pm 18.38)$ \\
5 & $120( \pm 4.94)$ & $1433( \pm 10.60)$ & $1673( \pm 13.43)$ \\
6 & $75( \pm 8.48)$ & $1397( \pm 9.24)$ & $1538( \pm 12.64)$ \\
\hline
\end{tabular}

Turbidity of control (culture without surfactant) was 1785 NTU

$p$ value in all experiments was $<0.05$ except to the data marked by asterisk 

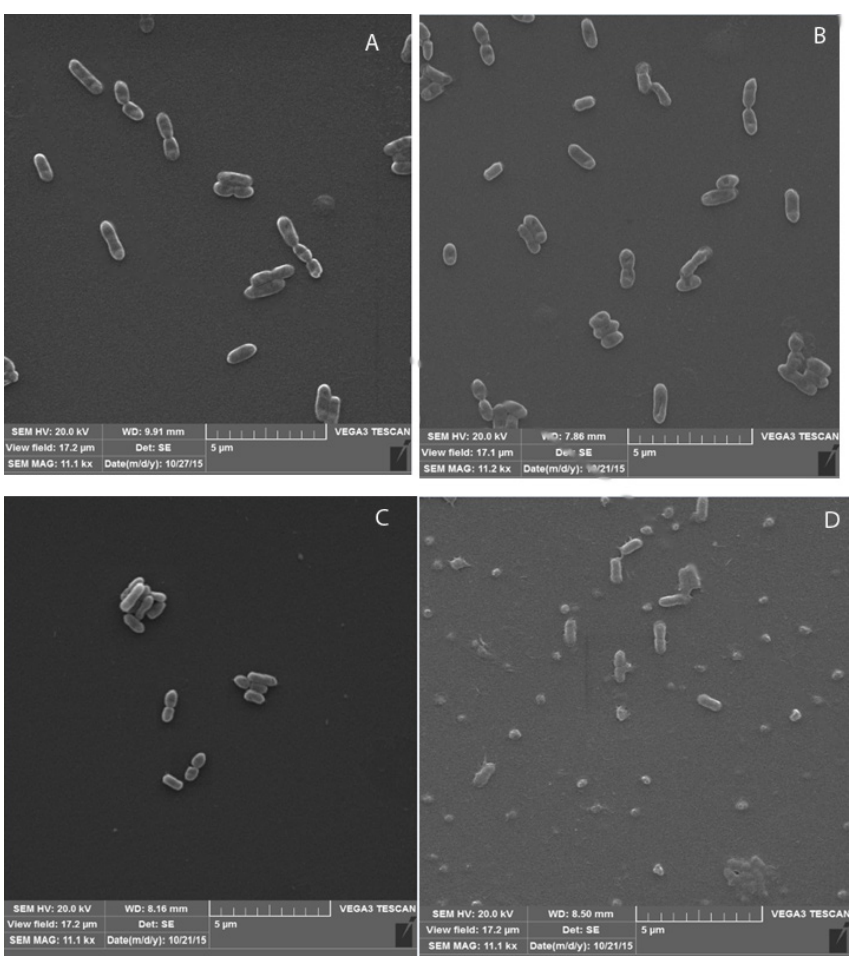

Figure 2. Scanning Electron Micrographs of Xanthomonas campestris in absence and presence of surfactants (with 5\% $\mathrm{v} / \mathrm{v}$ concentration), A: control (without surfactant), B: Tween 80, C: Tween 20, D: Triton X100.

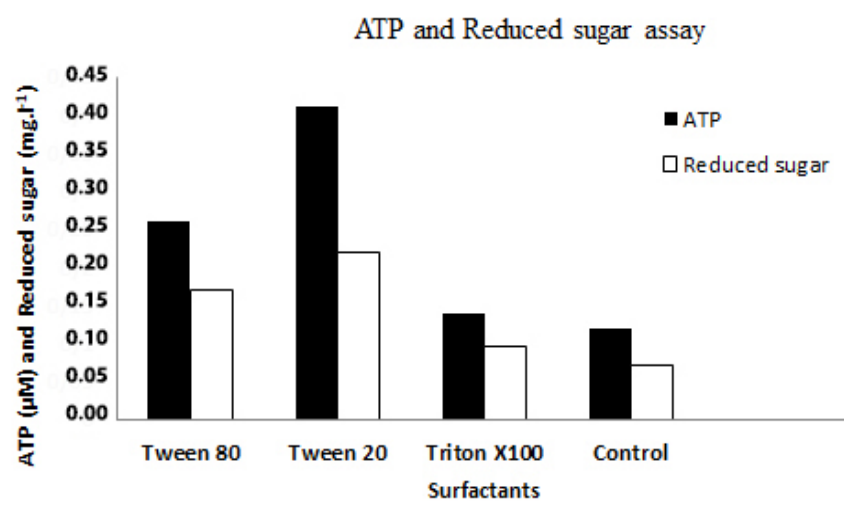

Figure 3. Amounts of ATP $(\mu \mathrm{M})$ and reduced sugar $\left(\mathrm{mg} . \mathrm{L}^{-1}\right)$ leakage in culture supernatants have been shown as a result of the surfactant application. Tween 80 and Tween 20 showed statistically significant difference with the control in leaking the ATP and reduced sugars to the culture supernatant.

showed no signs of oligosaccharides, mannose or glucuronic acid leakage.

\subsection{Structural Changes in Biopolymer}

Pyruvate content and molecular weight of xanthan were used as indicators of structural changes in the final product in response to surfactant application.
The results showed that the pyruvate content of all surfactant-treated cultures were the same as control $(2.05 \% \mathrm{w} / \mathrm{w})$; except to that of Triton X100 (1.94\% $\mathrm{w} / \mathrm{w})$. In all cases the molecular weight of purified xanthan samples which were extracted from cultures containing different surfactants was higher than that of control. The molecular weights of samples in the presence of Tween 80, Tween 20, Triton X100 and control were 59, 39, 27 and 23 million Da, respectively.

\section{Discussion}

The results from present study showed the negative effects of Tween 20 and Triton X100 on xanthan production and its viscosity. However, Tween 80 showed positive effects and improved xanthan gum production and viscosity. Each of the surfactants in Tween series has three polyethylene glycol groups and one fatty acid residue in their structure. The fatty acid substitutions in Tween 20 and Tween 80 are lauric acid and oleic acid, respectively. In contrast to oleic acid, lauric acid is less frequent fatty acid residue in bacterial cells and its antimicrobial activity against a number of bacteria has been shown in the literature. Hamedi et al. studied the effect of fatty acids on Saccharopolyspora erythraea and reported that lauric acid is more toxic than oleic acid (19). Nakatsuji et al. reported the antimicrobial activity of lauric acid against Propionibacterium acnes (20). In present study, GC Mass experiments showed that Tween 20 is dissociated and molecules of lauric acid were released in the culture medium (data not shown here).

Nguyen et al, studied the effect of detergents on secretion of extracellular proteins and reported that fatty acids in polysorbates (Tweens) play an important role in the formation of positive or negative interactions with phospholipids that expanded the pores in the cell membrane (21).

Some researchers argued that surfactants help to increase production by wetting the cell envelope and enhance the sorption of nutrient $(22,23)$. We believe that it can be true in case of fungi and other microorganisms possessing thick and condensed cell walls. In gram negative bacteria, such as Xanthomonas campestris, interactions between surfactants and the cell barriers, i.e. both of the inner and outer membranes, result in cell damage and an increased leakage degree. Leakage was evident with Tween 20 caused the highest amount of ATP release to the culture medium. Johnston et al. just speculated that after damaging of membrane, the leakage of low molecular weight compounds (purines, pyrimidines, pentoses, inorganic phosphate) are followed by the leakage of larger 
cellular constituents e.g. ATP (25). Sucrose was the main carbon source in this study that is going to be converted to monosaccharides by the bacterium and in control is going to be consumed as the energy source; absent from the culture supernatant. While, the use of surfactants demonstrated the presence of reduced sugars in the culture supernatants that is indicative of sugar leakage and damage to the cell barriers. SEM revealed shrinkage in size of the bacterial cells by 3.5 folds in varieties of shapes from rod to round, yet again another evidence of bacterial leakage. Similar results have been reported elsewhere, which are the results of membrane pore expansion and micelle formation $(1,21,24)$.

Earlier reports about the role of surfactants in xanthan production were somewhat contradictory (3-4), possibly due to the differences in strains and fermentation conditions: mixing and aeration.

Tritons have shown to be toxic on bacterial growth (4, 19), perhaps by increase in membrane permeability (9). Here, culture turbidity was diminished in the presence of surfactants, esp. Triton X100 that indicates a sharp decline in biomass.

While Galindo and Salcedo (3) and Janas et al. (4) and other researchers mainly provide extrinsic evidence for the effect of nonionic surfactants on xanthan gum production, the present study revealed that surfactants directly exert changes in the bacterial cells which result in greater xanthan production and showed that some of nonionic surfactants can be used to obtain better quantity and quality of xanthan gum. These positive effects can be provided by addition of surfactants in idiophase. According to our experiments, neither growth nor xanthan production was occurred when different surfactants were added to the culture medium within trophophase period of the fermentation (i.e. the first $24 \mathrm{~h}$ ), even at very low concentrations.

\section{Conflict of interest}

The authors declare that there is no conflict of interest.

\section{References}

1. García-Ochoa F, Santos VE, Casas JA, Gómez E. Xanthan gum: production, recovery, and properties. Biotechnol $A d v$. 2000;18(7):549-579. doi:10.1016/S0734-9750(00)00050-1.

2. Ghashghaei T, Soudi MR, Hoseinkhani S. Optimization of xanthan gum production from grape juice concentrate using Plackett Burman design and Response Surface Methodology. Applied Food Biotechnol. 2016;3(1):15-23.

3. Galindo E, Salcedo G. Detergents improve xanthan yield and polymer quality in cultures of Xanthomonas campestris. Enzyme Microb Technol. 1996;19:145-149. doi:10.1016/01410229(95)00215-4.

4. P. Janas, W. Gustaw, S. Mleko, J. Pielecki. Effect of detergents on xanthan production during batch and continuous cultivation of Xanthomonas campestris NRRL B-1459. Technologia Alimentaria. 2003;2(1):125-133.

5. Srivastava RAK, Mathur SN. Effect of media composition on synthesis and excretion of o-amylase by a thermophilic Bacillus sp. AK-2. Indian J Microbial. 1985;23(2):110-116. doi: 10.1590/ S1516-89132003000100018.

6. Fisher BE, Kleber HP. Isolation and characterization of the extracellular lipase of Acinetobacter calcoaceticus 69 V. J Basic Microbiol. 1987;27(8):427-432. doi: 10.1002/ jobm.3620270807.

7. Asther M, Corrieu G, Drapron R, Odier E. Effect of Tween 80 and oleic acid on ligninase production by Phanerochaere chrysosporium INA-12. Enzyme Microb Technol. 1987;9:245249. doi: 10.1016/0141-0229(87)90024-X

8. Stutzenberger FJ. Component-specific stimulation of cellulase secretion in Thermomonospora cutvafa by the surfactant Tween 80. J Appl Bacterial. 1987;63(3):239-244. doi:10.1016/01410229(87)90024-X.

9. Alakomi HL, Skytt E, Saarela M, Mattila-Sandholm T, Latva-Kala K, Helander IM. Lactic acid permeabilizes Gramnegative bacteria by disrupting the outer membrane. Appl Environ Microbiol. 2000;66(5):2001-2005. doi: 10.1128/ AEM.66.5.2001-2005.2000.

10. Roseiro JC, Esgalhado ME, Amaral-Collaço, Emery AN. Medium development for xanthan production. Process Biochem. 1992;27(3):167-175. doi:10.1016/0032-9592(92)87005-2.

11. Ben Salah R, Chaari K, Besbes S, Ktari N, Blecker C, Deroanne C, Attia H. Optimization of xanthan gum production by palm date (Phoenix dactylifera L.) juice by-products using response surface methodology. Food Chem. 2010;121(2):627- 633. doi:10.1016/j.foodchem.2009.12.077.

12. Kang SY, Kim KD, Hong JK, Hyun HN, Jeun YC. The role as inoculum sources of Xanthomonas citri pv. citri surviving on the infected Satsuma mandarin fruits. J Microbiol. 2014; 52(5):422-426. doi: 10.1007/s12275-014-3366-z.

13. Shehni SA, Soudi MR, Hosseinkhani S. Improvement of xanthan gum production in batch culture using stepwise acetic acid stress. Afr J Biotechnol. 2011;10(83):19425-19428. doi: 10.5897/AJB11.1794.

14. Nankai H, Hashimoto W, Miki H, Kawai S, Murata K, Microbial system for polysaccharide depolymerization: enzymatic route for xanthan depolymerization by Bacillus sp. Strain GL1. Appl Environ Microbiol. 1999;65(6):2520-2526. doi: 10.1006/ abbi.1996.9851.

15. Gonçalves C, Rodriguez-Jasso RM, Gomes M, Teixeira JA, Belo I. Adaptation of dinitrosalicylic acid method to microtiter plates. Anal Methods. 2010;2(12):2046-2048. doi: 10.1039/ C0AY00525H.

16. Duckworth M, Yaphe W. Definitive assay for pyruvic acid in agar and other algal polysaccharides. Chem Ind. 1970;23:747748.

17. Viturawong Y, Achayuthakan P, Suphantharika M. Gelatinization and rheological properties of rice starch/xanthan mixtures: Effects of molecular weight of xanthan and different salts. Food Chem. 2008;111(1):106-114. doi:10.1016/j. foodchem.2008.03.041.

18. Torres LG, Flores F, Galindo E. Apparent yield stress of xanthan solutions and broths. Bioprocess Eng. 1995;12(1):41- 46. doi: 10.1007/BF01112992.

19. Hamedi J, Makhdumi KA, Darabi HR. Suitable nonionic surfactants for the erythromycin production 
by Saccharopolyspora erythraea. Journal of Science. 2006;32(1):41-46.

20. Nakatsuji T, Kao MC, Fang JY, Zouboulis CC, Zhang L,Gallo RL, Huang CM. Antimicrobial property of lauric acid against Propionibacterium acnes: Its therapeutic potential for inflammatory acne vulgaris. $J$ Invest Dermatol. 2009;129(10):2480-2488. doi: 10.1038/jid.2009.93.

21. Nguyen QD, Sujto NM, Bujna E, Hoschke A, Rezessy-szabo JM. Effects of medium composition and process parameters on the production of Eextracellular inulinase by Thermomyces lanuginosus. Food Technol Biotechnol. 2013;51(1):36-44.

22. Desai JD, Patel HC, Desai AJ. Effect of Tween series surfactants on alkaloid production by submerged cultures of
Claviceps species. J Ferment Technol. 1986;64 (6):499-501. doi:10.1016/0385-6380(86)90073-7.

23. Mizrahi S, Miller G. Role of Glycols and Tweens in the production of ergot alkaloids by Claviceps paspali. J Bacteriol. 1969;97(3):1155-1159.

24. Wei G, Li Y, Du G, Chen J. Effect of surfactants on extracellular accumulation of glutathione by Saccharomyces cerevisiae. Process Biochem. 2003;38(8):1133-1138. doi:10.1016/S00329592(02)00249-2.

25. Johnston MD, Hanlon GW, Denyer SP, Lambert RJW. Membrane damage to bacteria caused by single and combined biocides. $J$ Appl Microbiol. 2003;94(6)1015-1023. doi: 0.1046/j.13652672.2003.01923.x. 